Article

\title{
The Sustainable Care Model for an Ageing Population in Vietnam: Evidence from a Systematic Review
}

\author{
Loi Tan Nguyen ${ }^{1}$, Phouthakannha Nantharath ${ }^{2}$ and Eungoo Kang ${ }^{3, *}$
}

1 Becamex School of Business, Eastern International University, Binh Duong 75114, Vietnam; loi.nguyen@eiu.edu.vn

2 College of Local Administration, Khon Kaen University, Khon Kaen 40002, Thailand; nantha@kku.ac.th

3 Business and Technology, DBA, Saint Mary's University of Minnesota, Minneapolis, MN 55404, USA

* Correspondence: exkang14@gmail.com

check for updates

Citation: Nguyen, L.T.; Nantharath, P.; Kang, E. The Sustainable Care Model for an Ageing Population in Vietnam: Evidence from a Systematic Review. Sustainability 2022, 14, 2518. https://doi.org/10.3390/su14052518

Academic Editors: Valentina Hlebec, Giovanni Lamura and Marco Socci

Received: 29 December 2021

Accepted: 17 February 2022

Published: 22 February 2022

Publisher's Note: MDPI stays neutral with regard to jurisdictional claims in published maps and institutional affiliations.

Copyright: (C) 2022 by the authors. Licensee MDPI, Basel, Switzerland. This article is an open access article distributed under the terms and conditions of the Creative Commons Attribution (CC BY) license (https:// creativecommons.org/licenses/by/ $4.0 /)$.

\begin{abstract}
Social demographic studies in Vietnam have shown a growing trend of an ageing population. Demographic trends project that one third of the Vietnamese population will be aged 65 years and older by 2050. Vietnam is a country where the majority of the elderly live with their children, with little savings and pension. The purpose of this review was to explore existing literature on models of care for an ageing population and provide evidence to develop a care model that is suitable for the ageing community in Vietnam. A systematic review utilizing the Preferred Reporting Items for Systematic Reviews and Meta-Analyses (PRISMA) framework was carried out. An extensive literature search was performed, with a focus on articles and other materials with relevance to elderly care in Vietnam in terms of socio-economic, demographic, and associated factors based on comprehensive data sources. The review found that there is a lack of evidence of professional practice for caring for the aged in Vietnam. There also is a lack of evidence of government support for the limited community initiatives to support the ageing. There exist no community models of care for the ageing population in Vietnam. From a global perspective, there exist alternative models of care options to support the elderly through various care models, such as living in assisted-care facilities, home care, and other assistance. Inter-professional practice care models and health services were found to be essential for an ageing population. There is limited literature specifically for the care of an ageing population in Vietnam. Most of the available literature on care models for the aged is drawn from developed countries. The review offers insights into the development of care models for the elderly in Vietnam, with the need for inter-professional efforts in practice settings to support the ageing Vietnamese population. The reviewed literature agrees on the developing global challenges due to ageing. Despite the existing literature on care models for the ageing, there is a lack evidence-based care models concerning the current and future needs of elderly care in middle- and lower-income economies like Vietnam. More evidence is required to establish evidence for best care models for the elderly in developing economies.
\end{abstract}

Keywords: ageing; population; models of care; sustainable welfare; health policy; developing economies

\section{Introduction}

The ageing population phenomenon is experienced globally, with considerable effects on all aspects of life. While becoming a growing global issue, ageing populations pose new challenges to global health systems, health policies, and medical resource allocation [1]. Since 2005, the global share of the population aged above 60 is showing an upward trend across all countries and regions. It has been projected that the global elderly population will triple from 1980 to 2025, increasing from 259 million to 761 million in less than five decades [2]. The fast-ageing global population leads to higher dependency rates and requires health and social care systems to transform to address the new population demographics. The increasing trends of an ageing population have been observed both 
in developing and developed countries, with the majority of the current statistics and projected numbers coming from developed countries and regions.

The global concerns of an ageing population have described the demographic shift in industrial and post-industrial countries as a "time bomb". The rapidly growing percentage of the elderly fits Vietnam in both the descriptions of a developing and a developed country. While the World Trade Organization (WTO) framework maintains Vietnam under the status of a developing country [3], some trade partners such as the United States have reclassified its list of developing nations based on industrial development. The last few decades have seen a rapid increase in the ageing population across the Southeast Asian (SEA) region and especially in the fast-growing economy such as Vietnam [4]. The World Health Organization [5] reported that, in 2017, approximately $9.8 \%$ of population in SEA was aged 60 or above, a number expected to reach $13.7 \%$ and $20.3 \%$ by 2030 and 2050, respectively. Meanwhile, a report published in the East Asia Forum estimated that over $10 \%$ of Vietnam's population consisted of people aged 60 years and older [6]. Minh Ngoc Nguyen [7] reported that between 2015 and 2020 the share of population aged above 65 in Vietnam grew from $6.7 \%$ to $7.9 \%$, and it will continue to show an increasing trend towards 2050. The population share of the people aged 60 years and older is projected to account for $20.4 \%$ of the total population of Vietnam by 2038 [8]. Based on these demographic trends, it is projected that by 2050, 29 million people will be aged above 60 years, representing one third of the country's population, with those over 80 years of age projected to account for at least $6 \%$ of the entire population [9].

The existing literature has shown negative views of ageing populations, with economic, social, and policy implications. A number of studies have highlighted the reasons for considering the ageing population as an issue and a challenge of global and national concern from socio-economic and health perspectives. The aging population not only reduces the numbers of laborers contributing to economic activity, but also increases the demand for pension, health care, and policy reform.

Economically, there exist many negative stereotypical associations with old age and reduced economic productivity. For instance, an ageing population has been viewed to be less productive [10]. An ageing population expressed reduced levels of delivery in work settings as compared to a younger population. An ageing workforce has a negative impact on economic growth [11]. Cristea, Noja, Dănăcică, \& Ştefea, [12] have linked the ageing population to reduced labor productivity and increased poverty risk. Similarly, Lukyanets, Okhrimenko, \& Egorova [13] noted that an ageing population reduced the labor force and increased the dependency level, with an impact on economic stability. The literature further concluded that ignorance towards the ageing population has implications on state budget stability and threatens a country's economic prosperity.

Socially, an increase in the proportion of elderly people in a society as compared to those generating an income is viewed negatively, as it can contribute to an increase in the dependency ratio. Reduced productivity and increased dependency levels are viewed as a poverty risk [12]. The need to reduce the dependency ratio makes it essential to develop policies and care models to mitigate the social and economic burden brought about by the ageing population and enable the participation of elderly workers in income generation [14] Rahman [15] linked a rapidly growing ageing population to the pressure on governments to increase external borrowing to support internal national affairs. A recent study by Wang and Zhou [16] concluded that the rapid increase of an ageing population not only increases the old-age dependency ratio but significantly adds to the pressure on social security and public services. As elaborated by Danh [4], the majority of the elderly population in Vietnam often are taken care of by their children and their families. The World Bank [17] reported that the age dependency ratio in Vietnam in 2020 was $45 \%$ and was projected to increase in the coming years. The national survey by HelpAge International [9] reported that over $56 \%$ of self-assessed elderly people mostly refer to themselves as weak or very weak, with a relatively high percentage of them requiring emotional and physical support. 
A majority of the Vietnamese aged population, though receiving social allowance, have been reported to be living alone and destitute [9].

In addition to economic and social challenges, the fast-growing ageing population of Vietnam raises concerns regarding health care, welfare, and pensions for the elderly. This comes at a time when the Vietnamese government is focusing on economic integration, with a demand for a large labor force. The government of Vietnam has put in place various measures within the health service delivery system to meet the needs of the elderly. For example, the government has constituted a policy framework that focuses on the health and security of the elderly and participation of the elderly in local community activities [18] Under these policies, the elderly have a right to health care and access to specialized healthcare services. The elderly are given priority access to health care, with those above 80 years of age eligible for homecare services. Vietnam's elderly care policies also provide health security programs by giving free health insurance cards to poor elderly people and monthly allowances to the elderly living alone and under the care of low-income households. As a majority of the elderly people in Vietnam live in rural areas under the care of family members and the community, the government has put in place policies that ensure the inclusion and participation of the elderly in local community activities to improve local political and economic stability.

With a lack of adequate policies in place, an ageing population poses greater demands and pressure on local healthcare systems, with little or no inputs to support the strengthening of the system from the elderly patients. Evidence drawn from reports by the Institute for Health Metrics and Evaluation [19] and the Vietnam Ministry of Health [20] on the burden of non-communicable diseases (NCDs) in Vietnam indicated that older people in Vietnam account for approximately $89 \%$ of lost disability-adjusted life years (DALYs), with around $88 \%$ of reported deaths due to NCDs drawn from the aged majority. According to the Vietnam Ministry of Health [20], the elderly are prone to diseases such as cardiovascular diseases, especially stroke and ischemic heart disease; cancers, especially lung, tracheal, liver, stomach, and colon cancers; and chronic obstructive pulmonary diseases (COPD). These diseases have been identified as the leading causes of mortality among older people. Furthermore, older people are more likely to suffer from joint pain, dizziness, cough, migraines, respiratory and gastrointestinal diseases, and complications, with a number of aged people reporting hypertension symptoms [21,22]. Cognitive impairment diseases have been reported to increase as a population ages [23]. The health status of the elderly people, especially in rural Vietnam, have increased demand for healthcare services, further straining the Vietnamese social and healthcare systems. Littlejohns and his colleagues [24] noted that, from a global perspective, healthcare systems are under pressure to meet the needs of ageing populations and develop interventions within a spectrum of limited resources.

Although the government of Vietnam may adapt in order to manage the concerning burdens from an ageing population, many challenges continue to arise, as ageing is a continuous process. Moreover, despite the stipulated policies for the care of elderly people, the government of Vietnam is unable to provide full support in terms of elderly care within communities. The majority of the responsibility for caring for the elderly is relegated to the household economy and family members. As per the current trends, Vietnam is expected to deal with the same problem of a growing elderly population as in already developed countries such as Japan, Germany, Portugal, USA, Italy, Korea, and China. It is therefore important for the country to explore models of care for the aged and tap into the potential of the elderly to contribute to society rather than increase the dependency ratio. The purpose of this review paper is twofold: (i) to draw evidence from existing research on how ageing populations could become economic burdens for Vietnam and what policy obstacles are faced by its government, and (ii) to present supporting knowledge for developing and sustaining a new care model for Vietnam's ageing population that is, importantly, based on the country's societal values. It is hoped that the findings from this review will shed light 
on factors that could play a significant role in formulating the model of care and contribute to future studies in a similar field of interest.

\section{Literature Review}

A demographic transition is occurring across the globe, as population ageing is a global phenomenon [25]. The global population's age structure is shifting upward, as a considerable share of the population is ageing [26]. The fast-growing elderly population has been linked to improved mortality rates and a decrease in fertility rates in most parts of the world [27]. This demographic transition has been influenced by various social-economic factors, such as economic growth and per capita gross national income higher rates of urbanization increased life expectancy [16], improved education and use of better health technology [28], reduced birth rates, child mortality, and death rates [29]. It is predicted that the majority of the developing and developed countries will suffer major shifts in population structures and have a higher share of the elderly than the young generations [30]. Though the ageing population is a global phenomenon, a higher percentage of the elderly are living in already developed countries. However, recent projections indicate that the majority of the world's elderly will be living in currently developing nations by 2050 [31]. The differences in the ageing population between developed and developing countries has been associated with the countries' preventative and therapeutic approaches in managing diseases associated with age [32].

\subsection{The Political Economy Theory and the Social Conflict Theory}

Seminal contributions to the understanding of the ethical, medical, socio-economic, and socio-psychological aspects of an ageing population have been made in early theories of sociology. Assumptions often drawn from such theories include the decline of physical and psychological abilities and the change in social roles, which the growing society must take into account. Caring for the elderly and the models of care for the ageing can be analyzed from the perspectives of various sociological theories, for instance, the Political Economy Theory and the Social Conflict Theory.

One of the most important strands in the study of ageing in recent years has been the Political Economy perspective, pioneered by the prior study [33]. Reflecting on the views of Estes [34], the Political Economy theory takes into account the role of the state and capitalism as factors of inclusion or as marginalization of older people within an economy. The theory further expands on insights into how economic and political systems define the dynamics of power and existence of inequalities within a society [35]. The existence of policies in a society that define income, health, and social security, based on political and economic systems, explain the struggles and conflict between societies and systems of power and control that lead to social stratification such as gender, age, race, and class [36]. Such policies, for instance, policies affecting older people, can be viewed as a reflection of such social stratifications based on age, social class, and in some cases, gender. Based on arguments by Estes [33,34], the global phenomena of ageing and the elderly within a society are a part of the society and can never be viewed as any different from other forces that define and contribute to the demographics of the larger society. The Political Economy theory thus can be utilized to understand the delivery of elderly care in the broader political and economic contexts and develop effective strategies to improve the health and life chances of all older adults [37].

The Social Conflict theory presents social life as a competition based on race, sex, class, and age. This competition as per the ideologies of Karl Marx leads to conflict and social change. The focus of the theory is mainly the distribution of resources, power, and inequality [38]. A social-conflict analysis is based on the idea that access to opportunities and social resources differs for people in different age categories. Conclusively, age is a dimension of social stratification. The social-conflict approach claims that our industrialcapitalist economy creates an age-based hierarchy. Using a Marxist approach, Spitzer [38] argued that a capitalist society devalues the class of people within that society who are 
considered to be less productive. Physical capabilities decline as people age to the extent that older people do not work [39]. The lack of productivity input for the society, especially income, from the elderly population has been labelled as mildly deviant [38]. Social-conflict analysis also draws attention to various dimensions of social inequality within the elderly population and how differences in class, race, ethnicity, and gender define successful ageing [40].

\subsection{The Functions and Structural Changes of Families}

Research on the ageing population has considered the family as the essential feature in the approach to the social challenges brought about by population ageing [41]. Family members and the wider community are considered as primary and immediate sources of care to support the elderly population [42]. From a contemporary discourse, it has been argued as to whether the caring for the elderly by family members is a societal obligation or a societal burden [43-45].The family as a unit of the society is noted to have undergone a series of considerable changes that have disrupted the traditional functions of the family, relationships within a family, and the family relationship with the society [46]. The societal and family changes have a positive and negative impact on the provision of informal family care for the elderly based on how they impact the mechanism of caring for the aged [47].

Previous research has viewed these structural changes of families from both positive and negative perspectives. For instance, the structural changes have seen women join paid employment and being considered in national welfare policies and positively encouraging sharing of family care responsibilities [48]. From a social capital perspective, the prior study [49] viewed these social and structural changes within family functions as good, based on their impact on family business development. Though this applies to contemporary families in urban areas, the case for family care and structure remains complicated in rural regions. Drawing from the perspectives of structural family changes in China, the prior study [50] concluded that though structural changes had a profound influence of differences in generational, geographic, and gender perspectives on family values, they improved filial piety.

However, these structural changes of families and newer demands off family members are considered to be a growing threat to the carrying capacity of the elderly by families. Families are also experiencing geographic mobility, further putting pressure on familybased care [41]. Geographic mobility may influence the child-parent proximity, with a possibility of reduced individual involvement in caring for older families [51]. Education as a factor of structural changes in families has been found to erode patrilineal and traditional gender values [50].

Further of note and of concern are the demographic trends and transitions involving a shrink in age distributions and a shift from young to old, reflecting profound changes in risks and behaviors for individuals and families over the economic life cycle [52]. Moreover, the increasing number of aged family members increases financial vulnerability and poses a threat to the availability of family caregivers [53]. The previous study [44] argued that the inclusion of family members in caring for the aged improves their quality of life, suggesting that the inclusion of family members in facility-assisted care and policies should be encouraged. The increased responsibility of family members caring for an ageing nonproductive member of the family has been linked to a considerable decline in the caregivers' health, well-being, and daily life $[42,54]$.

\subsection{Global Elderly Care Systems}

The improvement of life expectancy in most developed countries has seen people living into advanced ages, creating dependency and an increase in care needs and the need for long-term care [55]. A majority of the elderly care systems have been modelled along the medical, socio-economic, and socio-psychological aspects of an ageing population. Investment considerations for care facilities have been made based on the functional capacities of the elderly. For instance, the Swedish model of elderly care is based on the 
principle of "age-in-place", which involves having aged people live under home care for the longest possible time [56], with publicly assisted homecare funding and assistance [57]. Elderly people have worse health outcomes and have higher need for medical attention as compared to younger people [58]. Previous research has identified comorbidities to be common among the aged, further adding to their medical needs. For example, Smit and his colleagues [59] concluded that people ageing with HIV infections were more likely to develop age-related non-communicable diseases. The existence of comorbidities in old age increases the need for medical care.

Meinow and his associates [55] argued that age, gender, the type of household, and income are intertwined in old age and impact the need for and design of elderly care. Meinow et al. [55] also showed that women likely have greater need for institutionalized long-term care (LTC) than men, while further research has proven that women stay longer in long-term care facilities than men, with differences in age and fragility across genders [60-62]. Gender has also been noted to influence a variance in quality of life of the elderly [63]. Socioeconomic inequalities have been noted to exist in the provision, distribution, and utilization of long-term care among the elderly across different regions [64,65]. The frameworks of elderly care, approachability, and affordability based on social class and income have been noted as barriers to access health care among the elderly [66].

In recent years, the development of models of care for the elderly in developed countries, especially in Europe and the United States, has been expanded into alternative approaches, such as the so-called Green Care model. In practice, Green Care is an approach of care that incorporates a farm-like setting to facilitate care for individuals in need, both mentally and physically. The prior research [67] described Green Care as the use of animal and/or plants in psychological, educational, social, or physical interventions. This type of care is often facilitated within naturalistic surroundings, such as natural parks, gardens, farms, etc. $[68,69]$. While many developing countries, including Vietnam, may have numerous potential settings to develop care farming, a lack of knowledge and adequate supports would make the implementation of such care models far from being realized.

\subsection{Elderly Care in the Asian Region}

Most Asian countries are experiencing a transition of their population to a higher proportion being composed of elderly people aged above 65 years. The upwards shift in the population age structure poses emerging challenges of shifting disease burdens associated with old age, a strain on national health systems due to increased expenditure on health and long-term care, a reduced labor force, dissaving, and a potential economic crisis due to factors associated with reduced elderly productivity and old-age income security [25]. Most Asian countries face problems arising from an ageing population similar to those experienced in other global societies, such as dementia, frailty, long-term care, home care, and polypharmacy [70]. Frailty is linked to loss of function of body systems leading to vulnerability. The living conditions of a majority of the people in some Asian countries have influenced the onset of premature frailty and old-age-related conditions. Furthermore, previous studies have linked an ageing population to diseases such as chronic stress, depression, distress, and negative affects to well-being domains such as decreased quality of life and loss of social relationships [30]. As has been previously reported in literature, all health outcomes are collectively perceived as a burden to caregivers [71,72]. Experiences of social exclusion and lower quality of living spaces induce premature ageing.

The growing number of the elderly requires the reformation of Asian health systems to meet the needs of older people [32]. Long-term care policies have become critical for governments, as countries are faced with societal changes due to the growing population share of the elderly, implying a significant need for long-term care (LTC) [73]. There are a lot of unmet elderly care needs across the Asian region, highlighting the need for family, community, and government efforts to achieve long-term care for the fast-growing ageing population [74]. Bloom and his associates [25] pointed out that the ageing population challenges are unprecedented in developing countries, as most of the current institutional 
and social arrangements are not friendly to ageing populations and demographic shifts. There is also no universal model to address the global challenges of an ageing population, as the needs of the aged population vary across countries, level of income, and health conditions of the elderly [32].

\section{Methodology}

The papers included in the review were selected through a process guided by the preferred reporting items for systematic reviews and meta-analyses (PRISMA) statement [75]. The eligibility criteria for the papers selected was fixed to focus on full-length research papers published between 2010 and 2021.

\subsection{Databases Used and Search Strategies Applied}

Studies were searched in NCBI, Medline, and Emerald databases. The overall search strategy for the papers for this review was guided by a preliminary review of related literature. The literature review helped identify the relevant research terms and phrases for the studies to be included. The search terms and phrases included elderly care, elderly care models, elderly care policies, elderly care in Vietnam, elderly care models in Vietnam, and Vietnam's elderly care policies. As the database search was expected to produce a high number of studies with both relevant and irrelevant studies, quality assessment criteria were designed, which focused on research methods, data analysis and location of the study as guides to the extraction of relevant studies. The inclusion of the search term "in Vietnam" with all other search terms was made compulsory to reduce the results of irrelevant studies and records.

\subsection{Quality and Effect Measures}

Out of the 54 papers meeting the inclusion criteria, 17 articles met the criteria and were assessed based on their methodological quality. The quality of the articles based on research design, sample population, sampling methods, measurement, and data analysis were evaluated using a self-developed 12 question scale emphasizing the study approach relating to elderly care and the description of being highly relevant to the subject and region of interest.

The total number of points scored by each study was divided by 12 (See Table 1). The choice of inclusion was based on the study's rating. Scores were awarded as follows: studies scoring below 0.50 were rated as weak, studies scoring 0.50 to 0.74 were rated as moderate, and studies that scored above 0.75 were rated as strong.

Table 1. Study approach and description.

\begin{tabular}{|c|c|c|}
\hline & Study Approach and Description & Scores \\
\hline \multirow{6}{*}{$\begin{array}{l}\text { Study Approach to Describing } \\
\text { Elderly Care }\end{array}$} & Does the study focus on elderly care? & $0.0-1.0$ \\
\hline & Does the paper focus on elderly care in Vietnamese communities? & $0.0-1.0$ \\
\hline & Was the study conducted in Vietnam? & $0.0-1.0$ \\
\hline & Does the study clearly state the context of the study? & $0.0-1.0$ \\
\hline & $\begin{array}{l}\text { Does the study's conclusion support reasonable care model } \\
\text { recommendations? }\end{array}$ & $0.0-1.0$ \\
\hline & $\begin{array}{l}\text { Does the study state socio-economic and demographics of an ageing } \\
\text { population in the Vietnamese context? }\end{array}$ & $0.0-1.0$ \\
\hline \multirow{6}{*}{ Study Description } & Are the study's participants clearly explained? & $0.0-1.0$ \\
\hline & Are the study's data analysis methods clearly stated? & $0.0-1.0$ \\
\hline & Does the study cover relatable dimensions of elderly care in Vietnam? & $0.0-1.0$ \\
\hline & Does the paper state the country of origin? & $0.0-1.0$ \\
\hline & Is the study in the English language? & $0.0-1.0$ \\
\hline & Is the study available in full text? & $0.0-1.0$ \\
\hline & Total Scores & Sum Score/12 \\
\hline
\end{tabular}




\section{Data Collection}

The Figure 1 indicates studies' workflow of identification, screening, and inclusion. The selection of the articles from the databases was manually done, which allowed the application of filters based on language, region of study, and a custom publication range.

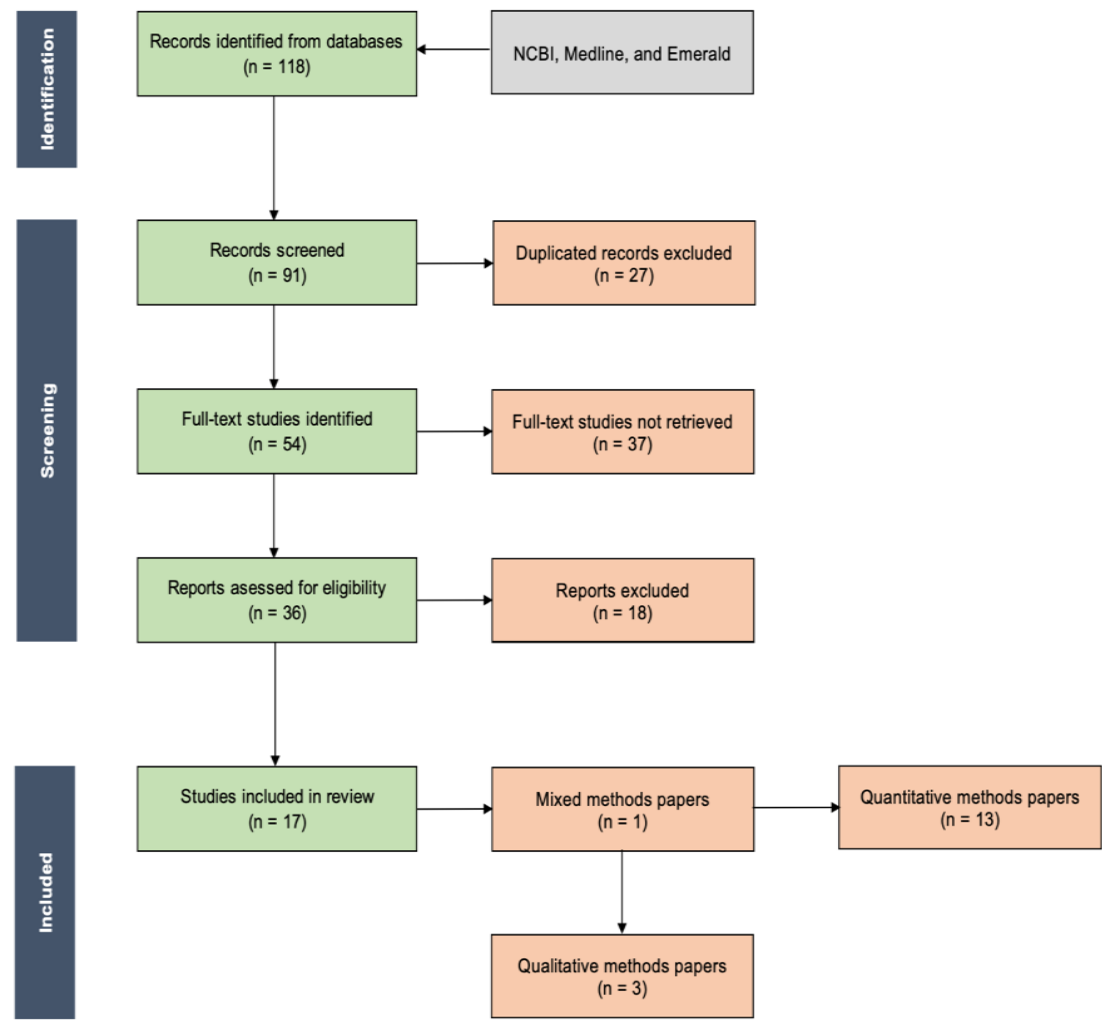

Figure 1. Workflow of studies' identification, screening, and inclusion.

\section{Results and Findings}

\subsection{Descriptive Analysis}

Research and review papers were the most preferred $(n=16)$, while a thesis paper that met the inclusion criteria was included $(n=1)$ (See Table 2$)$.

Table 2. Analysis of the retrieved articles.

\begin{tabular}{|c|c|c|c|}
\hline Authors & $\begin{array}{c}\text { Country of Study, } \\
\text { Methodology, and Data } \\
\text { Analysis }\end{array}$ & Participants & $\begin{array}{c}\text { Dimensions of Elderly Care } \\
\text { Studied }\end{array}$ \\
\hline $\begin{array}{l}\text { Hoi, Thang, and Lindholm } \\
\text { (2011) }\end{array}$ & $\begin{array}{l}\text { Vietnam; Quantitative; } \\
\text { Multivariate analysis }\end{array}$ & People aged above 60 years & $\begin{array}{l}\text { Socioeconomic determinants } \\
\text { of the activities of daily living } \\
\text { ADL index }\end{array}$ \\
\hline Thanh and Lindholm (2012) & $\begin{array}{c}\text { Vietnam; Quantitative; Stata } \\
\text { software version } 9.2\end{array}$ & $\begin{array}{l}\text { Households with members } \\
\text { aged above } 60 \text { years }\end{array}$ & $\begin{array}{l}\text { Vietnam healthcare funds for } \\
\text { the poor policy }\end{array}$ \\
\hline Binh (2012) & $\begin{array}{l}\text { Vietnam; Qualitative; } \\
\text { Qualitative analysis }\end{array}$ & Not stated & Family care function \\
\hline Hoang (2015) & $\begin{array}{c}\text { Vietnam, Mixed; } \\
\text { Multivariate analysis }\end{array}$ & Over 60 years old & Models of care \\
\hline $\begin{array}{l}\text { Ha, Le, Khanal, and Moorin } \\
\text { (2015) }\end{array}$ & $\begin{array}{l}\text { Vietnam; Quantitative; } \\
\text { Multivariate } \\
\text { Logistic Regression }\end{array}$ & Over 60 years old & $\begin{array}{l}\text { Multi-morbidity and } \\
\text { social determinants }\end{array}$ \\
\hline Meyer et al. (2015) & $\begin{array}{l}\text { United States; Qualitative; } \\
\text { Thematic Analysis }\end{array}$ & Caregivers above 18 years old & $\begin{array}{l}\text { Sociocultural context of } \\
\text { caregiving experiences }\end{array}$ \\
\hline
\end{tabular}


Table 2. Cont.

\begin{tabular}{|c|c|c|c|}
\hline Authors & $\begin{array}{c}\text { Country of Study, } \\
\text { Methodology, and Data } \\
\text { Analysis }\end{array}$ & Participants & $\begin{array}{c}\text { Dimensions of Elderly Care } \\
\text { Studied }\end{array}$ \\
\hline Mwangi et al. (2015) & $\begin{array}{c}\text { Vietnam; Quantitative; } \\
\text { Descriptive and Analytical } \\
\text { Statistical Analysis }\end{array}$ & Over 60 years old & $\begin{array}{c}\text { Chronic diseases, prevalence, } \\
\text { socio-demographic factors, } \\
\text { and healthcare expenditure }\end{array}$ \\
\hline $\begin{array}{l}\text { Tran, Nguyen, Nong, and } \\
\text { Nguyen (2016) }\end{array}$ & $\begin{array}{l}\text { Vietnam; Quantitative; } \\
\text { Multi-methods analysis }\end{array}$ & Over 45 years old & $\begin{array}{c}\text { Health status, health service } \\
\text { utilization in remote and } \\
\text { mountainous areas }\end{array}$ \\
\hline Bang et al. (2017) & $\begin{array}{l}\text { Vietnam; Quantitative; } \\
\text { Multi-methods analysis }\end{array}$ & $\begin{array}{l}\text { Cross-sectional ( } 15-60 \text { years } \\
\text { and above) }\end{array}$ & $\begin{array}{l}\text { Health status and } \\
\text { health demand }\end{array}$ \\
\hline $\begin{array}{l}\text { Van Nguyen, Van Nguyen, } \\
\text { Duc Nguyen, Van Nguyen, } \\
\text { and The Nguyen (2017) }\end{array}$ & $\begin{array}{l}\text { Vietnam; Quantitative; } \\
\text { Multivariate methods }\end{array}$ & Over 60 years old & $\begin{array}{l}\text { Differences in quality-of-life } \\
\text { analysis }\end{array}$ \\
\hline Tran Tuyen and Vu Van (2018) & $\begin{array}{l}\text { Vietnam; Quantitative; } \\
\text { Regression analysis }\end{array}$ & Over 50 years old & Housing and life satisfaction \\
\hline Pham et al. (2019) & $\begin{array}{l}\text { Vietnam; Quantitative; Multi } \\
\text { methods analysis }\end{array}$ & Elderly people (60+ years) & $\begin{array}{c}\text { Gender differences, quality of } \\
\text { life, and health services } \\
\text { utilization }\end{array}$ \\
\hline T.H. Nguyen et al. (2019) & $\begin{array}{l}\text { Vietnam, Quantitative; } \\
\text { Multivariate Logistic } \\
\text { Regression }\end{array}$ & Over 60 years old & $\begin{array}{c}\text { Establishing elderly activity } \\
\text { centers, preferences and } \\
\text { willingness to pay }\end{array}$ \\
\hline Vu et al. (2019) & $\begin{array}{c}\text { Vietnam, Quantitative; } \\
\text { Multivariable Logistic and } \\
\text { Tobit Regression }\end{array}$ & Physicians and nurses & $\begin{array}{l}\text { Knowledge and attitude } \\
\text { toward geriatric palliative care }\end{array}$ \\
\hline T.A. Nguyen et al. (2020) & $\begin{array}{c}\text { Vietnam; Qualitative; Not } \\
\text { specified }\end{array}$ & $\begin{array}{l}\text { Vietnamese dementia } \\
\text { stakeholders }\end{array}$ & Dementia action plan \\
\hline Chau (2020) & $\begin{array}{c}\text { Vietnam; Quantitative; Not } \\
\text { specified }\end{array}$ & $\begin{array}{l}\text { Households with members } \\
\text { aged above } 60 \text { years }\end{array}$ & Role of family in elderly care \\
\hline Danh (2021) & $\begin{array}{c}\text { Vietnam; Quantitative; } \\
\text { Descriptive statistical analysis }\end{array}$ & $50-65$ years & Impact on economy \\
\hline
\end{tabular}

Regarding the region of the study settings, both the rural and urban settings and aspects of the Vietnamese ageing population were sufficiently presented in the studies included. The rural regions of Vietnam were the most presented $(n=9)$, followed by urban and mixed settings $(n=7)$, and the diaspora region $(n=1)$.

The studies focused on the elderly population, with a majority of the studies drawing samples from Vietnamese populations aged above 60 years. A majority of the studies drew the participants from household and community populations aged 60 years and above $(n=9)$, above 50 years $(n=2)$, above 45 years $(n=1)$, and from 15 to 60 years $(n=1)$; from caregivers aged 18 to 60 years $(n=1)$; from clinical healthcare specialists $(n=1)$; and other from secondary data $(n=2)$.

In terms of study methodology, qualitative, quantitative, and mixed research methods were utilized. Quantitative methods were applied in most of the included studies $(n=13)$, followed by qualitative methods $(n=3)$, and the mixed methods approach $(n=1)$.

\subsection{Synthesis of Review Results}

The first consideration made during the synthesis of the study results was the theoretical consideration made in each paper. Out of the 17 studies included, two presented a theoretical basis of the focus of the study as per the domain of an elderly population. The papers built the case for the study based on previous literature on elderly care to develop the conceptual frameworks for the studies based on the role, impact, and interventions for an ageing population as per the social, economic, and political systems of Vietnam. Two studies had a clear theoretical framework and developed the work in light of the modernization theory and the social exchange theory [76] and the Kamp model [77]. 
Studies explored various topics relatable to the five domains of elderly population: physical, psychological, social, spiritual, and functional domains. Topics included quality of life $[77,78]$, gender differences, quality of life and use of health services [78], role of family in elderly care [79], impact on economy [4,22], diseases, comorbidities and sociodemographic factors [21,22,78,80-82], sociocultural experiences [83], activities of daily living among the elderly [84], attitudes towards geriatric palliative care [85], modes of elderly during social change [76,86], housing and satisfaction in life [87], and elderly health status and healthcare demand [88]. These domains of elderly care as presented by the studies form the basis of developing a sustainable elderly care model in the face of a fast-ageing Vietnamese population. The table below (Table 3) presents the focus of the studies included and the respective main findings.

Table 3. Synthesis review of selected articles.

Authors

Hoi et al. (2011)

Thanh and Lindholm

Binh (2012)

Hoang (2015)

Ha et al. (2015)

Meyer et al. (2015)

Mwangi et al. (2015)

Tran et al. (2016)

Bang et al. (2017)

Van Nguyen et al. (2017)
Focus of Study on Elderly Care and Sample Size

Needs and socioeconomic determinants of ADLs in rural settings; 2240

Healthcare Funds for the Poor policy (HCFP) on healthcare expenditure; 3957

Family function in elderly care in Vietnam; Secondary data

Modes of Vietnamese elderly care; 60

Social determinants multimorbidity of among elderly Vietnamese; 2400

Dementia caregivers' experiences from a sociocultural context; 10

Prevalence of chronic diseases among elderly Vietnamese in rural areas.

Social demographic factors and healthcare expenditures; 2873

Health status and utilization of health services in remote Vietnam; 200

Elderly health status, healthcare demand, health status, and health-related quality of life (HRQoL) in rural Vietnam; 713

Difference in quality of life and associated factors among the elderly in rural Vietnam; 402
A majority of older people in rural areas who need help receive enough support in daily care.

The need for care is greater in disadvantaged groups. Family offers needed support.

Though HCFP increased the use of communal health stations, little change was identified in healthcare expenditures. HCFP has enabled poor elderly Vietnamese to access basic healthcare.

Family members play the basic role of caring for the elderly. Elderly care is a role of the family, society, and the government. Modernization associated with the decline in family support adversely affects the status of the well-being of the elderly in Vietnam. Elderly are not totally dependent on their children for support and care but are actively part of the family's web of support.

Multimorbidity instances were identified in nearly $40 \%$ of older people.

Multimorbidity is higher among illiterate elderly people living in rural areas than in urban areas.

Lack of work and physical activity contribute to higher instances of multi-morbidities.

Filial piety was influential in caregiving.

A sense of loss/grief or trauma was pervasive.

Caregivers had clear sources of stress and sources of support.

Elderly people suffer from one or more common chronic disease (CCDs).

Healthcare expenditure is higher for elderly Vietnamese living with CCDs.

Vietnamese living in remote areas were found to have a high prevalence of health problems.

Remote areas experience both social and structural barriers in access to health services.

Gender differences affect functionality

Women tend to have more functional limitations than men

HRQoL is determined by age, self-rated health status, BMI, and the number of non-communicable diseases (NCDs).

Elderly men have a higher level of quality of life $(\mathrm{QoL})$ than that of their female counterparts. This includes higher quality of physical health, psychological health,

and environment, with significant correlation with factors such as aged $\geq 80$ years, following Buddhism and Christianity, having better connection, and without illness in the past 6 months. 
Table 3. Cont.

Authors Focus of Study on Elderly Care and Sample Size

Tran Tuyen and Vu Van (2018)

Pham et al. (2019)

T.T.H. Nguyen et al. (2019)

Vu et al. (2019)

Chau (2020)

Danh (2021)
Role of family in elderly care

Housing and life satisfaction; 4007

Gender differences and quality of life; 523

Utilization of health services in rural Vietnam

Willingness of urban elderly people to join activity centers; 121

Geriatric health professionals, attitudes towards geriatric palliative care; 161

Development of a Vietnamese national dementia plan; 270

Ageing population and the economy; 40
Main Finding

Investing in houses was linked to well-being gains and increased satisfaction in life.

Elderly women have poorer health and quality of life. Health needs vary across gender.

Social support positively affects health outcomes.

Though a majority of elderly Vietnamese are willing to pay for

AC centers, income and social factors influence their willingness to pay.

Caregiver knowledge influenced their attitudes.

Attitudes determine quality of geriatric palliative care.

Training focused on pain, dyspnea, and gastrointestinal issue management needs to be provided to geriatric health professionals.

The dementia action plan basics include use of international experience, strong political and healthcare leadership, the

provision of international support to promote dementia awareness and development of a national dementia plan, and inclusion of multi-sectoral stakeholders.

Vietnamese still have a strong negative attitude toward elderly care homes.

The traditional role of the family in elderly care is still deeply maintained.

A majority of the elderly in the rural Vietnam lack material accumulation during their retirement age.

A majority of elderly Vietnamese living in rural areas are prone to illnesses.

Healthcare expenditure is higher among the elderly than the young generations.

\section{Discussion}

Seventeen articles were found to meet the selection criteria for this systematic review focused on developing a model for elderly care in Vietnam. Analysis of the main findings indicate that eight studies mentioned the basic approaches to elderly care in Vietnam, with six studies linking family-based care as the basic model of elderly care in Vietnam $[4,76,79,83,84,89,90])$ and two studies reporting filial piety as the most influential factor of family caregiving for the elderly $[83,84]$. Five studies out of the 17 reviewed studies explored the prevalence of multiple illnesses among the elderly in rural Vietnam $[22,77,80,90,91]$, with the reviewed studies linking gender differences, income, lifestyles differences in rural and urban Vietnam, the existence of other commonly ignored illnesses, and lack of work and physical activity to the issue of multimorbidity among the elderly in rural Vietnam. Five studies explored health-related quality of life among the elderly in Vietnam and the associated factors; these studies discussed gender differences, age, self-rated health status, BMI, and the number of non-communicable diseases (NCDs) $[77,78]$. Studies also reported on the socio-economic and political determinants of quality of life and reported that social support systems [80,87], gender $[77,78]$ and material accumulation [87] were linked to the satisfaction of life among the elderly and health outcomes among the elderly. Other important aspects that were deemed important to the development of a Vietnamese model of elderly care included the impact of the elderly on the economy on the basis of elderly care and an ageing population, assessed based on elderly care and health expenditures [22], dementia as an elderly disease and the development of a national dementia action plan [89], caregiver attitudes and caregiver support [83], and attitudes and willingness to pay for activity centers [82]. Each of these factors was only identified in a single article. The family model of elderly care was noted to occur across a 
majority of the included studies, making it the most preferred and effective model of elder care in Vietnam.

\subsection{Vietnam's Elderly Care Model}

Traditional family-based models of care for older people across Vietnam are based on Vietnamese traditional family and community principles. In ten of the selected studies, family members were mentioned as the basic caregivers to older family members [4,78-80,82,83,86-88,90,92]. As it is indicated by this review, the choice of the family-based elderly care system across Vietnam is influenced by filial piety [83]. Family and household elderly care arrangement was noted to be substantial across Vietnam, as family members were noted to provide the required social support $[84,89]$, with elderly care viewed as a role for the family and community $[79,83,84]$. A study by Hoi et al. [84] made it clear that family care for the elderly was the most preferred model, as it best supported disadvantaged groups.

Other than family-based elderly care, a study by Thanh and Lindholm [86] reported that the Vietnamese government implemented Health Care Funds for the Poor policy (HCFP), aimed at assisting low-income elderly households to have access to health care and to reduce elderly healthcare expenditures. In this study, HCFP was found to significantly promote healthcare utilization and reduce healthcare expenditure for the elderly. Additionally, as dementia has been identified to be one of major cognitive diseases affecting an ageing population [22,85,91], a study by Nguyen et al. [89] suggested the development and implementation a national dementia plan to promote dementia awareness and offer support to dementia caregivers.

\subsection{The Need of Daily Elderly Care in Vietnam}

The reviewed studies link the fast-ageing Vietnamese population to the growing need for elderly care. Different socioeconomic and political factors and characteristics of an ageing population have been identified to lead to the need for daily elderly care in Vietnam. Functional disability was identified in seven studies as a reason for the need for daily elderly care in Vietnam, which is consistent with the existing literature $[4,22,78,82,84,87]$. The need for daily care was identified as varying for specific activities of daily living for elderly people, such as basic ADLs including bathing and dressing, instrumental ADLs including cooking and travelling, and intellectual ADLs including reading and writing [84]. The prevalence of comorbidities and other chronic diseases among the elderly, especially in rural Vietnam, accounted for the second leading factor for the need for daily elderly care in Vietnam $[4,22,78,80,87]$. Six studies identified the decrease in cognitive abilities or dementia as another cause for the need for daily elderly care in Vietnam $[83-85,87,89,90]$.

\subsection{The Determinants of Elderly Care}

A strong link was established relating socioeconomic and demographic factors as determinants of elderly care in Vietnam. This includes needs according to sex, educational level, marital status, living arrangement, household head status, working status, household size, area of residence, and household economic conditions [84]. Health related Quality of life (HRQOL) and Quality of life (QoL) in general were inexorably linked to income and financial well-being [90] with the quality of living observed to be higher among older people who had higher income. Healthcare expenditure, access to health services, gender differences, and comorbidity were reported to significantly affect HRQOL and all aspects of QoL of elderly people $[22,78,82,87,88,90]$. A study by Bang et al. [88] relates HRQOL to age, self-rated health status, BMI, and the number of non-communicable diseases (NCDs) an elderly person has. Caregiver attitudes were further noted to determine elderly care across Vietnam [83,85]. Elderly care was also found to be determined by health and functional differentials based on gender and other social differentials, with women reported across six studies to have poor functional and health outcomes [77,78,82,84,85,90]. A study by Hoi et al. [84], reported that elderly care was determined by age group, sex, educa- 
tional level, marital status, household membership, working status, household size, living arrangement, residential area, household wealth, poverty status, and chronic illnesses.

\subsection{Challenges and Current Frameworks towards Model Care for the Aged}

Many of the challenges identified in the reviewed studies are related to the systemic, sociocultural, and psychological factors of Vietnamese communities and the ageing population. Four studies established that there exist huge differences in the quality of life between elderly men and women $[77,78,84,88]$. Furthermore, these studies cumulatively note that there exist differences among elderly women's health and care demands based on level of education and socioeconomic status. This creates a challenge to the development and implementation of a gender-focused elderly care model.

Another challenge of the current care model for the aged is linked to the fast-ageing population and the increased demand for geriatric specialists against the actual number of available specialists. As the population ages, the number of caregivers reduces [79]. Coordination of social and financial support for elderly care is not readily available in Vietnam. One study identified that there is a lack of caregiving and care coordination support, indicating that some aged people did not receive any or enough social support in ADLs [84]. Domestic caregivers have been noted to be affected negatively at some point, whether psychologically and emotionally; however, they lack adequate support to manage mental and emotional health outcomes [83].

The attitudes towards elderly care remain rather negative. The elderly, due to their need for attention, higher health expenditure, and lack of financial inputs, have largely been viewed as a burden to domestic caregivers [4]. One study reported there lacked adequate awareness and professional caregiver skills and knowledge in Vietnam to meet the growing demand for elderly palliative care [85].

\section{Conclusions}

In conclusion, this review paper found that Vietnam is experiencing a rapid increase in the proportion of the ageing population coupled with a growing demand for elderly care across the country. The issues related to an ageing population continue to be relevant topics of discussion across social, economic, and political spheres. Although a good number of studies exploring the attributes and factors of a sound elderly care model were identified, this review paper found no evidence of what seems to be the most suitable care model being implemented in Vietnam. However, this review found that while family care arrangements were the basic models of elderly care across Vietnam, family-based care was found to put a strain on family economics, as well as the social and psychological well-being of both the elderly and the caregivers. The development of a universally adoptable care model in Vietnam focused on institutional elderly care seems to be a goal yet to be achieved, as there exist socioeconomic and regional disparities in elderly care needs. Another issue is the differences that exist in health and social well-being demands for elderly women and men.

This review did not find evidence of an alternative approach to care, such as Green Care or care farming, which are being developed and implemented in European countries and in the United States. As Vietnam is still very much in the infancy stage of dealing with ageing population concerns, its government and policymakers would rather focus on conventional and local approaches, such as promoting community and family-based models of care.

\section{Limitations and Recommendations for Future Research}

First, a majority of the reviewed studies only focused on the care of aged people living in households, ignoring those institutionalized in elderly care centers. Second, it was impossible to conduct a meta-analysis, as the findings of the studies included did not clearly describe the domains of elderly care studied or covered diverse domains of elderly care, which were largely descriptive. Third, there was a lack of standardized search terms for elderly care models in Vietnam, making it hard to search for articles in 
major databases. Fourth, although most of the studies focused on the perspectives of the elderly, enabling the development of statistical causality for the elderly and social support, health and wellbeing, there is a need to develop cross-sectional research that draws from the perspectives of the young caregivers and other stakeholders, focused on caregivers and older people's psychological well-being, life satisfaction, and self-rated health under household care arrangements. Future research aimed at developing sustainable and easily adoptable elderly care models in rural and urban settings should consider cross-sectional, randomized, and controlled study samples drawn from rural and urban settings as well as elderly people in both household and institutional care.

Author Contributions: Data curation, L.T.N.; Investigation, L.T.N. and P.N.; Methodology, L.T.N. and E.K.; Resources, P.N.; Software, L.T.N. and P.N.; Supervision, E.K.; Validation, L.T.N.; Writingoriginal draft, L.T.N. and P.N.; Writing-review \& editing, E.K. All authors have read and agreed to the published version of the manuscript.

Funding: This research received no external funding.

Institutional Review Board Statement: Not applicable.

Informed Consent Statement: Not applicable.

Data Availability Statement: Not applicable.

Conflicts of Interest: The authors declare no conflict of interest.

\section{References}

1. Li, J.; Han, X.; Zhang, X.; Wang, S. Spatiotemporal evolution of global population ageing from 1960 to 2017. BMC Public Health 2019, 19, 1-15. [CrossRef] [PubMed]

2. Isa, F.M.; Noor, S.; Wei, G.W.; Hussain, S.D.B.S.; Ibrahim, H.M.; Ahmdon, M.A.S. Exploring the facet of elderly care centre in multiethnic Malaysia. PSU Res. Rev. 2020; ahead-of-publish. [CrossRef]

3. Samuel, P. Preferential Trade Benefits: US Delists Vietnam as Developing Nation. Available online: https://www.vietnambriefing.com/news/preferential-trade-benefits-us-delists-vietnam-developing-nation.html/ (accessed on 28 December 2021).

4. Danh, N.T. Aging Population and Its Impacts on Economy of Vietnam. Turk. J. Comput. Math. Educ. (TURCOMAT) 2021, 12, 1681-1685. [CrossRef]

5. World Health Organization, Ageing and Health Report. 2018. Available online: https://www.who.int/news-room/fact-sheets/ detail/ageing-and-health (accessed on 7 September 2021).

6. Tong, L. Vietnam Struggling with Ageing Population. 2017. Available online: https://www.eastasiaforum.org/2017/01/25 / vietnam-struggling-with-ageing-population/ (accessed on 28 December 2021).

7. Nguyen, M.N. Share of Ageing Population in Vietnam 2015. 2021. Available online: https://www.statista.com/statistics/713671 /vietnam-forecast-ageing-population/ (accessed on 28 December 2021).

8. General Statistics Office. Population Ageing and Older Persons in Viet Nam. 2021. Available online: https://www.gso.gov.vn/ en/data-and-statistics/2021/08/population-ageing-and-older-persons-in-viet-nam/ (accessed on 19 September 2021).

9. HelpAge International. Ageing Population in Vietnam. 2019. Available online: https://ageingasia.org/ageing-populationvietnam/\#keyfacts (accessed on 16 December 2021).

10. White, M.S.; Burns, C.; Conlon, H.A. The Impact of an Aging Population in the Workplace. Work. Health Saf. 2018, 66, 493-498. [CrossRef] [PubMed]

11. Huang, W.-H.; Lin, Y.-J.; Lee, H.-F. Impact of Population and Workforce Aging on Economic Growth: Case Study of Taiwan. Sustainability 2019, 11, 6301. [CrossRef]

12. Cristea, M.; Noja, G.G.; Dănăcică, D.E.; Ştefea, P. Population ageing, labour productivity and economic welfare in the European Union. Econ. Res.-Ekon. Istraživanja 2020, 33, 1354-1376. [CrossRef]

13. Lukyanets, A.; Okhrimenko, I.; Egorova, M. Population Aging and Its Impact on the Country's Economy. Soc. Sci. Q. 2021, 102, 722-736. [CrossRef]

14. Guest, R. Population ageing and productivity: A survey with implications for New Zealand. N. Z. Econ. Pap. 2014, 48, 153-168. [CrossRef]

15. Rahman, H.S.W.B.H.A. Impact of Population Ageing on Economic Growth, Healthcare Expenditure and Labor Productivity in Malaysia. Ph.D. Thesis, Universiti Putra Malaysia, Seri Kembangan, Selangor, Malaysia, 2018.

16. Wang, Y.; Zhou, C. Promoting social engagement of the elderly to cope with aging of the Chinese population. Biosci. Trends 2020, 14, 310-313. [CrossRef]

17. World Bank. Age Dependency Ratio (Percentage of Working-age Population) Vietnam. 2020. Available online: https://data worldbank.org/indicator/SP.POP.DPND?end=2020\&locations=VN\&start=1960\&view=chart (accessed on 13 September 2021). 
18. Oanh, T.M.T. The Role of Government in "Active Ageing” in Vietnam. 2021. Available online: https://www.mhlw.go.jp/english/ policy/affairs/asean/dl/11th_26_Presentation_Vietnam.pdf (accessed on 15 September 2021).

19. Institute for Health Metrics and Evaluation. The Global Burden of Disease: Generating Evidence, Guiding Policy. 2013. Available online: http://www.healthdata.org/sites/default/files/files/policy_report/2013/GBD_GeneratingEvidence/IHME_GBD_ GeneratingEvidence_FullReport.pdf (accessed on 31 August 2021).

20. Vietnam Ministry of Health. Joint Annual Health Review: Strengthening Prevention and Control of Non-Communicable Disease; Medical Publishing House: Ha Noi, Vietnam, 2015.

21. Dang, T.N.; Honda, Y.; Van Do, D.; Pham, A.L.T.; Chu, C.; Huang, C.; Phung, D.; Van, D.D. Effects of Extreme Temperatures on Mortality and Hospitalization in Ho Chi Minh City, Vietnam. Int. J. Environ. Res. Public Health 2019, 16, 432. [CrossRef]

22. Mwangi, J.; Kulane, A.; Van Hoi, L. Chronic diseases among the elderly in a rural Vietnam: Prevalence, associated sociodemographic factors and healthcare expenditures. Int. J. Equity Health 2015, 14, 1-8. [CrossRef]

23. Banovic, S.; Zunic, L.; Sinanovic, O. Communication Difficulties as a Result of Dementia. Mater. Socio-Med. 2018, 30, 221-224. [CrossRef] [PubMed]

24. Littlejohns, P.; Kieslich, K.; Weale, A.; Tumilty, E.; Richardson, G.; Stokes, T.; Gauld, R.; Scuffham, P. Creating sustainable health care systems. J. Health Organ. Manag. 2019, 33, 18-34. [CrossRef] [PubMed]

25. Bloom, D.E.; Canning, D.; Lubet, A. Global Population Aging: Facts, Challenges, Solutions \& Perspectives. Chall. Solut. Perspect. Daedalus 2015, 144, 80-92.

26. Fehlings, M.G.; Tetreault, L.; Nater, A.; Choma, T.; Harrop, J.; Mroz, T.; Santaguida, C.; Smith, J.S. The Aging of the Global Population. Neurosurgery 2015, 77, S1-S5. [CrossRef] [PubMed]

27. Yusuf, M.M.; Mohamed, S.; Basah, M.Y.A. The Impact of Ageing Population on Malaysian Economic Growth. ASM Sci. J. 2020, 13, 1-6. [CrossRef]

28. Halbac-Cotoara-Zamfir, R.; Cividino, S.; Egidi, G.; Salvia, R.; Salvati, L. Rapidity of Change in Population Age Structures: A Local Approach Based on Multiway Factor Analysis. Sustainability 2020, 12, 2828. [CrossRef]

29. Stolnitz, G. The Demographic Transition: From High to Low Birth Rates and Death Rates; Routledge: Oxford, UK, 2017 ; pp. 30-46.

30. Menike, H.R.A. Important Features of the Elderly Population in Sri Lanka. Res. Process. Int. J. Soc. Res. Found. 2014,2 , 29-38.

31. Röhr, S.; Pabst, A.; Riedel-Heller, S.G.; Jessen, F.; Turana, Y.; Handajani, Y.S.; Brayne, C.; Matthews, F.; Stephan, B.C.M.; Lipton, R.B.; et al. Estimating prevalence of subjective cognitive decline in and across international cohort studies of aging: A COSMIC study. Alzheimer Res. Ther. 2020, 12, 1-14. [CrossRef]

32. Cheng, X.; Yang, Y.; Schwebel, D.C.; Liu, Z.; Li, L.; Cheng, P.; Ning, P.; Hu, G. Population ageing and mortality during 1990-2017: A global decomposition analysis. PLoS Med. 2020, 17, e1003138. [CrossRef]

33. Estes, C.L. The Aging Enterprise: In Whose Interests? Int. J. Health Serv. 1986, 16, 243-251. [CrossRef]

34. Estes, C.L. The Aging Enterprise Revisited. Gerontol. 1993, 33, 292-298. [CrossRef] [PubMed]

35. Polivka, L.; Estes, C. The Aging Enterprise: A 40-Year Retrospective. Innov. Aging 2020, 4, 718-719. [CrossRef]

36. Polivka, L. The Political Economy of Aging Services in the United States Since the Aging Enterprise. Innov. Aging 2020, 4, 719. [CrossRef]

37. Portacolone, E.; Herd, P. The political economy of aging in the 21st century: The influence of carroll estes' scholarship in social gerontology. Innov. Aging 2018, 2, 368-369. [CrossRef]

38. Spitzer, S. Marxist Perspectives in the Sociology of Law. Annu. Rev. Sociol. 1983, 9, 103-124. [CrossRef]

39. Kim, C.-B.; Yoon, S.-J.; Ko, J. Economic Activity and Health Conditions in Adults Aged 65 Years and Older: Findings of the Korean National Longitudinal Study on Aging. Healthcare 2017, 5, 63. [CrossRef]

40. Amaral, F.M.; Soetjiningsih, C.H. Successful Aging of Elderly People in Low Economic Status Who Are Still Working and it is Related To Daily Activities and Hardiness. Psikodimensia 2019, 18, 28. [CrossRef]

41. Keating, N. Critical reflections on families of older adults. Adv. Gerontol. 2011, 24, 343-349.

42. Jarling, A.; Rydström, I.; Ernsth-Bravell, M.; Nyström, M.; Dalheim-Englund, A. A responsibility that never rests-The life situation of a family caregiver to an older person. Scand. J. Caring Sci. 2019, 34, 44-51. [CrossRef]

43. Igarashi, H.; Hooker, K.; Coehlo, D.P.; Manoogian, M.M. “My nest is full”: Intergenerational relationships at midlife. J. Ageing Stud. 2012, 27, 102-112. [CrossRef]

44. Puurveen, G.; Baumbusch, J.; Gandhi, P. From Family Involvement to Family Inclusion in Nursing Home Settings: A Critical Interpretive Synthesis. J. Fam. Nurs. 2018, 24, 60-85. [CrossRef] [PubMed]

45. Salvati, L.; Carlucci, M.; Serra, P.; Zambon, I. Demographic Transitions and Socioeconomic Development in Italy, 1862-2009: A Brief Overview. Sustainability 2019, 11, 242. [CrossRef]

46. Casares Garcia, E. Studies on the structural changes in family relationships. Portularia Rev. De Trab.Soc. 2008, 8, 183-195.

47. Van Groenou, M.I.B.; De Boer, A. Providing informal care in a changing society. Eur. J. Ageing 2016, 13, 271-279. [CrossRef]

48. Carrasco, C.; Rodriguez, A. Women, Families, and Work in Spain: Structural Changes and New Demands. Fem. Econ. 2000, 6, 45-57. [CrossRef]

49. Jamali, R.; Abedin, B. Effects of family functions and structural changes on family business development (social capital evidence). Int. J. Entrep. Small Bus. 2013, 18, 79. [CrossRef]

50. Hu, Y.; Scott, J. Family and Gender Values in China. J. Fam. Issues 2014, 37, 1267-1293. [CrossRef] 
51. Holmlund, H.; Rainer, H.; Siedler, T. Meet the Parents? The Causal Effect of Family Size on the Geographic Distance between Adult Children and Older Parents; IZA Discussion Papers; Institute for the Study of Labor (IZA): Bonn, Germany, 2009. [CrossRef]

52. Lee, R. The Demographic Transition: Three Centuries of Fundamental Change. J. Econ. Perspect. 2003, 17, 167-190. [CrossRef]

53. Suriyanrattakorn, S.; Chang, C.-L. Long-term care (LTC) policy in Thailand on the homebound and bedridden elderly happiness. Health Policy Open 2021, 2, 100026. [CrossRef]

54. Balbim, G.M.; Magallanes, M.; Marques, I.G.; Ciruelas, K.; Aguiñaga, S.; Guzman, J.; Marquez, D.X. Sources of Caregiving Burden in Middle-Aged and Older Latino Caregivers. J. Geriatr. Psychiatry Neurol. 2019, 33, 185-194. [CrossRef]

55. Meinow, B.; Wastesson, J.W.; Kåreholt, I.; Kelfve, S. Long-Term Care Use During the Last 2 Years of Life in Sweden: Implications for Policy to Address Increased Population Aging. J. Am. Med. Dir. Assoc. 2020, 21, 799-805. [CrossRef] [PubMed]

56. Schön, P.; Lagergren, M.; Kåreholt, I. Rapid decrease in length of stay in institutional care for older people in Sweden between 2006 and 2012: Results from a population-based study. Health Soc. Care Community 2015, 24, 631-638. [CrossRef] [PubMed]

57. Modig, K.; Lambe, M.; Ahlbom, A.; Ebeling, M. Excess mortality for men and women above age 70 according to level of care during the first wave of COVID-19 pandemic in Sweden: A population-based study. Lancet Reg. Health Eur. $2021,4,100072$. [CrossRef] [PubMed]

58. Schulz, M.; Czwikla, J.; Tsiasioti, C.; Schwinger, A.; Gand, D.; Schmiemann, G.; Schmidt, A.; Wolf-Ostermann, K.; Kloep, S.; Heinze, F.; et al. Differences in medical specialist utilization among older people in need of long-term care-Results from German health claims data. Int. J. Equity Health 2020, 19, 1-10. [CrossRef]

59. Smit, M.; Brinkman, K.; Geerlings, S.; Smit, C.; Thyagarajan, K.; van Sighem, A.; de Wolf, F.; Hallett, T. Future challenges for clinical care of an ageing population infected with HIV: A modelling study. Lancet Infect. Dis. 2015, 15, 810-818. [CrossRef]

60. Aaltonen, M.; Forma, L.; Rissanen, P.; Raitanen, J.; Jylhä, M. Transitions in health and social service system at the end of life. Eur. J. Ageing 2010, 7, 91-100. [CrossRef] [PubMed]

61. Forma, L.; Jylhä, M.; Pulkki, J.; Aaltonen, M.; Raitanen, J.; Rissanen, P. Trends in the use and costs of round-the-clock long-term care in the last two years of life among old people between 2002 and 2013 in Finland. BMC Health Serv. Res. 2017, 17, 668. [CrossRef]

62. Kang, H.; Hong, G.-R.S. Effect of Muscle Strength Training on Urinary Incontinence and Physical Function: A Randomized Controlled Trial in Long-term Care Facilities. J. Korean Acad. Nurs. 2015, 45, 35-45. [CrossRef]

63. Wongsawat, S. Predicting Factors for Quality of Life of Elderly in the Rural Areas. Int. J. Arts Sci. 2017, 9, 363.

64. Lera, J.; Pascual-Sáez, M.; Cantarero-Prieto, D. Socioeconomic Inequality in the Use of Long-Term Care among European Older Adults: An Empirical Approach Using the SHARE Survey. Int. J. Environ. Res. Public Health 2020, 18, 20. [CrossRef]

65. YongJae, L. Inequality Analysis of Regional Distribution of Long-Term Care Institutions for the Elderly. The Journal of Korean Long Term Care. 2021. Available online: http:/ / kiss.kstudy.com/thesis/thesis-view.asp?g=kissmeta\&m=exp\&enc=1E3059D5F2 5787DE13EC03D8016197C4 (accessed on 5 December 2021).

66. Doetsch, J.; Pilot, E.; Santana, P.; Krafft, T. Potential barriers in healthcare access of the elderly population influenced by the economic crisis and the troika agreement: A qualitative case study in Lisbon, Portugal. Int. J. Equity Health 2017, 16, 1-17. [CrossRef] [PubMed]

67. Haubenhofer, D.K.; Elings, M.; Hassink, J.; Hine, R.E. The Development of Green Care in Western European Countries. Explore 2010, 6, 106-111. [CrossRef] [PubMed]

68. Hine, R.; Peacock, J.; Pretty, J. Care farming in the UK: Contexts, benefits and links with therapeutic communities. Ther. Communities 2008, 29, 245-260.

69. Artz, B.; Davis, D.B. Green Care: A Review of the Benefits and Potential of Animal-Assisted Care Farming Globally and in Rural America. Animals 2017, 7, 31. [CrossRef]

70. Chen, L.; Akishita, M.; Kuzuya, M.; Kozaki, K.; Kojima, T.; Toba, K.; Ouchi, Y. Future perspective on active ageing from rapidly ageing Asian countries. Eur. Geriatr. Med. 2012, 3, S7-S8. [CrossRef]

71. Duarte, E.S.R.; Silveira, L.V.D.A.; Cítero, V.D.A.; Jacinto, A.F. Common mental disorder among family carers of demented older people in Brazil. Dement. Neuropsychol. 2018, 12, 402-407. [CrossRef]

72. Nishikawa, Y.; Niimura, H.; Ozaki, A.; Kimura, Y.; Morita, T.; Sawano, T.; Saito, H.; Tsubokura, M. Successful institutional care for behavioral and psychological symptoms of dementia in a repopulated area after the 2011 Fukushima disaster: A case report. Clin. Case Rep. 2018, 6, 2266-2270. [CrossRef]

73. Crawford, R.; Stoye, G.; Zaranko, B. Long-term care spending and hospital use among the older population in England. J. Health Econ. 2021, 78, 102477. [CrossRef]

74. Yeung, W.-J.J.; Thang, L.L. Long-Term Care for Older Adults in ASEAN Plus Three: The Roles of Family, Community, and the State in Addressing Unmet Eldercare Needs. J. Aging Health 2018, 30, 1499-1515. [CrossRef]

75. Moher, D.; Liberati, A.; Tetzlaff, J.; Altman, D.G.; PRISMA Group. Preferred reporting items for systematic reviews and meta-analyses: The PRISMA statement. PLoS Med. 2009, 6, e1000097. [CrossRef]

76. Hoang, C.T. Modes of Care for the Elderly in Vietnam: Adaptation to Change. Ph.D. Thesis, The Australian National University, Canberra, Australia, 2015.

77. Van Nguyen, T.; Van Nguyen, H.; Nguyen, T.D.; Van Nguyen, T.; Nguyen, T.T. Difference in quality of life and associated factors among the elderly in rural Vietnam. J. Prev. Med. Hyg. 2017, 58, E63-E71. [PubMed] 
78. Pham, T.; Nguyen, N.T.T.; ChieuTo, S.B.; Le Pham, T.; Nguyen, T.X.; Nguyen, H.T.T.; Nguyen, T.N.; Nguyen, T.H.T.; Nguyen, Q.N.; Tran, B.X.; et al. Sex Differences in Quality of Life and Health Services Utilization among Elderly People in Rural Vietnam. Int. J. Environ. Res. Public Health 2018, 16, 69. [CrossRef] [PubMed]

79. Binh, N.T. Function of taking care of elderly people in Vietnamese families at present time. Res. Humanit. Soc. Sci. 2012, 2, 49-54.

80. Ha, N.T.; Le, N.H.; Khanal, V.; Moorin, R. Multimorbidity and its social determinants among older people in southern provinces, Vietnam. Int. J. Equity Health 2015, 14, 50. [CrossRef]

81. Li, G.; Li, Z.; Lv, X. The ageing population, dependency burdens and household commercial insurance purchase: Evidence from China. Appl. Econ. Lett. 2020, 28, 294-298. [CrossRef]

82. Nguyen, T.T.H.; Nguyen, T.X.; Pham, T.; Nguyen, C.T.; Vu, G.T.; Nguyen, L.H.; Tran, B.X.; Vu, H.T.T.; A Latkin, C.; Ho, C.S.; et al. Establishing activity centers for elderly people in metropolitan areas of Vietnam: Preference and willingness-to-pay. J. Multidiscip. Health 2019, 12, 795-802. [CrossRef] [PubMed]

83. Meyer, O.L.; Nguyen, K.H.; Dao, T.N.; Vu, P.; Arean, P.; Hinton, L. The sociocultural context of caregiving experiences for Vietnamese dementia family caregivers. Asian Am. J. Psychol. 2015, 6, 263-272. [CrossRef]

84. Hoi, L.V.; Thang, P.; Lindholm, L. Elderly care in daily living in rural Vietnam: Need and its socioeconomic determinants. BMC Geriatr. 2011, 11, 81. [CrossRef] [PubMed]

85. Vu, H.T.T.; Nguyen, L.H.; Nguyen, T.X.; Nguyen, T.; Nguyen, T.N.; Nguyen, H.; Nguyen, A.; Pham, T.; Nguyen, C.; Tran, B.; et al. Knowledge and Attitude Toward Geriatric Palliative Care among Health Professionals in Vietnam. Int. J. Environ. Res. Public Health 2019, 16, 2656. [CrossRef] [PubMed]

86. Thanh, N.X.; Lindholm, L. Has Vietnam Health care funds for the poor policy favored the elderly poor? BMC Health Serv. Res. 2012, 12, 333. [CrossRef]

87. Tran, T.Q.; Van Vu, H. A microeconometric analysis of housing and life satisfaction among the Vietnamese elderly. Qual. Quant. 2017, 52, 849-867. [CrossRef]

88. Bang, K.-S.; Tak, S.H.; Oh, J.; Yi, J.; Yu, S.-Y.; Trung, T.Q. Health Status and the Demand for Healthcare among the Elderly in the Rural Quoc-Oai District of Hanoi in Vietnam. BioMed Res. Int. 2017, 2017, 4830968. [CrossRef] [PubMed]

89. Nguyen, T.A.; Pham, T.; Dang, T.H.; Hinton, W.L.; Nguyen, A.T.; Le Pham, T.; Crotty, M.; Kurrle, S.; Bui, Q.T.; Nguyen, H.; et al. Towards the development of Vietnam's national dementia plan-The first step of action. Australas. J. Ageing 2019, 39, 137-141. [CrossRef]

90. Tran, B.X.; Nguyen, L.H.; Nong, V.M.; Nguyen, C.T. Health status and health service utilization in remote and mountainous areas in Vietnam. Health Qual. Life Outcomes 2016, 14, 85. [CrossRef]

91. Bang, K.-S.; Tak, S.H.; Oh, J.; Yi, J.; Yu, S.-Y.; Trung, T.Q. Corrigendum to “Health Status and the Demand for Healthcare among the Elderly in the Rural Quoc-Oai District of Hanoi in Vietnam". BioMed Res. Int. 2019, 2019, 9590417. [CrossRef]

92. Chau, N.T.H. Studying about the family's role in taking care of the elderly in Vietnam today-Through the research in elderly care homes in Ho Chi Minh city. Sci. Technol. Dev. J. Soc. Sci. Humanit. 2020, 4, 324-335. [CrossRef] 